\title{
Diurnal Variation of Surface Radio Refractivity over Sokoto, North-western Nigeria
}

\author{
Mohammed Z Doko ${ }^{1}$, Oyedum O David ${ }^{2}$, Muhammad B Ladan ${ }^{3}$, Jibrin A Yabagi ${ }^{3}$, \\ Ndanusa Babakacha ${ }^{3}$, Abdullahi A Saba ${ }^{3}$, and Franscious Cummings ${ }^{4}$ \\ ${ }^{1}$ Corps Information Technology Office, Network \& Communication Unit, Federal Road Safety Corps, \\ National Headquarters Abuja, Nigeria \\ ${ }^{2}$ Department of Physics, Federal University of Technology, Minna, Nigeria \\ ${ }^{3}$ Department of Physics, Ibrahim Badamasi Babangida University, Lapai, Niger State, Nigeria \\ ${ }^{4}$ Electron Microscope Unit, University of the Western Cape, Private Bag X17, Bellville 7535, South \\ Africa \\ Corresponding E-mail: hazmeeacademy@gmail.com
}

Received 03-11-2021

Accepted for publication 23-12-2021

Published 27-12-2021

\begin{abstract}
The knowledge of good refractivity profile is vital for proper planning of terrestrial communication links; surface refractivity profile of a station is particularly required for enhanced planning and prediction of performance of terrestrial radio links especially in tropical regions where International Telecommunication Union Recommendations (ITU-R) has called for such local propagation data. The diurnal surface radio refractivity $\mathrm{N}_{\mathrm{s}}$ over Sokoto was investigated for a period of three years (2008-2010). High values of $\mathrm{N}_{\mathrm{s}}$ were recorded in the early morning hours while low values were recorded during afternoon hours. The least mean hourly $\mathrm{N}_{\mathrm{s}}$ varied between 270-280 N-units in January (a typical dry season month in Sokoto) while the mean maximum was recorded between 345-360 N- units in July (a typical rainy season month). Also, average seasonal variation of $\mathrm{N}_{\mathrm{s}}$ was 356-440 N-units in rainy season and 270-285 N-units in dry season. The result of this investigation also showed that relative humidity and temperature have major influence on the variation of surface radio refractivity, while pressure has relatively less influence. The study further showed that coverage of a radio transmitter of $200 \mathrm{~m}$ height may have a variation of up to $0.5 \mathrm{~km}$ between morning and afternoon hours in Sokoto.
\end{abstract}

Keywords: Refractivity; Temperature; Pressure; Relative humidity and Radio horizon

\section{INTRODUCTION}

A reliable operation of ground-based communication systems for various purposes largely depends on the physical state of the atmosphere. Changes in atmospheric propagation conditions may be manifested in the variation of radio field strengths and the radio horizon distance [1]. The propagation of radio wave through the troposphere is affected by varieties of natural phenomena caused by some meteorological parameters such as temperature, relative humidity and pressure [2]. The effects of the atmospheric parameters on the radio wave propagation can be observed from the study of radio refractive index, which varies considerably diurnally and seasonably in the tropics [3]. Radio wave propagation is determined by changes in the refractive index of air in the troposphere [4]. The changes in the value of the tropospheric refractive index can cause the path of the propagating radio wave to curve. The refractive effect is associated with the bending of electromagnetic 
waves and it is related to the distributions of vertical pressure, temperature and humidity in the atmosphere [5-6]. These atmospheric constituents introduce propagation delay in troposphere signal transmission. The delay is further caused by the amount of particles which constitute the atmosphere at that particular point [5]. The study of vertical profile of radio refractivity gradient in Akure, Nigeria, which reveals that radio refractivity is generally high during the rainy reason (March-October) at all the levels were reported by [4]. The worked on the variation of tropospheric surface refractivity over Nsukka in the South-East, Nigeria and observed that surface refractivity is generally higher in the wet season than in the dry season as reported by [7]. Furthermore, the study of diurnal and seasonal variations of surface refractivity over Nigeria, using four years in-situ meteorological data from eight stations in Nigeria and observed that the surface refractivity has higher values during the rainy season than during the dry season in all the locations as reported by [6]. Sokoto is a city in the Northwestern Nigeria located at $13^{\circ} 4^{\prime} 60^{\prime \prime} \mathrm{N}$ and $5^{\circ} 15^{\prime} 0^{\prime \prime} \mathrm{E}$, near the confluence of the Sokoto River and the Rima River. Sokoto is in the dry Sahel surrounded by sandy savannah and isolated hills with an annual average temperature of $28.3^{\circ} \mathrm{C}$. There are basically two distinct seasons in Sokoto, wet and dry seasons. The dry season starts from October to April in some parts and may extend to May or June in other parts. The wet season begins from May to September, or October. From late October to February, during the cold season, the climate is dominated by a dry, cold and fairly dusty wind called harmattan wind, blowing Sahara dust over the land. The dust dims the sunlight intensity significantly, thereby lowering temperatures considerably. Sokoto is one of the hottest cities in the world with maximum daytime temperatures generally around $40{ }^{\circ} \mathrm{C}$ in most of the year. The warmest months are February to April, where daytime temperatures can exceed $45{ }^{\circ} \mathrm{C}$. The highest recorded temperature was $47.2^{\circ} \mathrm{C}$ and minimum temperature was 38 ${ }^{\circ} \mathrm{C}$, which is also the highest recorded temperature in Nigeria. Considering the atmospheric conditions of Sokoto, this research work investigates the diurnal surface refractivity variation over Sokoto, using diurnal atmospheric parameters, and also determines the transition characteristics of radio signals between dry and wet seasons in the state.

\section{MATERIALS AND METHOD}

\section{A. Source of Data}

Three years (2008-2010) meteorological data for Sokoto were collected from the Centre for Basic Space Sciences (CBSS), Nsukka, Nigeria. The monthly mean of hourly surface radio refractivity over Sokoto were calculated using the meteorological data of temperature, pressure and the relative humidity collected from 2008-2010 with (2), whereas (3) and (4) were used to calculate the water vapour pressure and saturated vapour pressure. The effective earth radius factor (k-factor) and radio horizon distance were calculated using (6) and (8) respectively.

\section{B. Theory of Refractivity}

Use In standard atmospheric conditions near the earth's surface, the value of radio refractive index is approximately equal to 1.003 [8]. Since the value of refractive index of air is very close to unity, it is often expressed in parts per million by a quantity called the radio refractivity $\mathrm{N}$, which is related to refractive index $\mathrm{n}$ as in [4] and [9]:

$$
N=(n-1) \times 10^{6}
$$

\section{Radio Refractivity (N)}

Number The average value for the refractive index of air at ground level is around 1.003 , but it can easily vary from 1.0027 to 1.0035 . In view of the very small changes, a system was introduced to enable the small changes to be noted more easily. Units called ' $\mathrm{N}$ ' units are often used as given by (1) above. Atmospheric radio refractive index depends on air temperature, humidity, atmospheric pressure and water vapour pressure. Variation of any of these meteorological parameters can cause a significant variation on radio wave propagation, because radio signals can be refracted over whole signal path [10]. Pressure, temperature and humidity decrease as height increases in the atmosphere [11]. $\mathrm{N}$ depends on meteorological parameters such as pressure $(\mathrm{hPa})$, temperature $\mathrm{T}(\mathrm{K})$, and water vapour pressure $\mathrm{e}(\mathrm{hPa})$ and these are related by [9]:

$$
\begin{aligned}
& N=N_{d r y}+N_{\text {wet }} \\
& =\frac{77.6 P}{T}+\frac{3.75 \times 10^{5} e}{T^{2}} \quad(N-\text { units })
\end{aligned}
$$

Where, $\mathrm{P}=$ atmospheric pressure $(\mathrm{hPa}), \mathrm{T}=$ absolute temperature $(\mathrm{K})$, and $\mathrm{e}=$ water vapour pressure $(\mathrm{hPa})$.

The first part of (2) is called the dry term $\left(N_{d r y}\right)$, which is an index for the thermal seasonal changes and is fairly constant, while the second part is called the wet term $\left(N_{\text {wet }}\right)$ which depends on water vapour pressure, e (hPa) and temperature, $\mathrm{T}(\mathrm{K}) . N_{\text {wet }}$ is mainly responsible for the variability in $\mathrm{N}$ within the troposphere [1]. The relative humidity of air is a function of both its water content and temperature and it is normally expressed as a percentage [12].

The relationship between water vapour pressure and relative humidity is given by [13] in (3) and (4):

$$
\begin{aligned}
& e=\frac{H e_{s}}{100} \\
& e_{s}=a \exp \left(\frac{b t}{t+c}\right)
\end{aligned}
$$

$\mathrm{H}$ is the relative humidity in $\%, e_{s}$ is the saturated vapour pressure $(\mathrm{hPa})$ at temperature $\mathrm{t}$ in degree Celsius, $\mathrm{a}, \mathrm{b}, \mathrm{c}$ are coefficients given as [9]:

For water, $\mathrm{a}=6.1121, \mathrm{~b}=17.502$ and $\mathrm{c}=240.97$, while $\mathrm{a}$ $=6.115, \mathrm{~b}=22.452$ and $\mathrm{c}=272.55$ for ice.

Valid between $-20{ }^{\circ} \mathrm{C}$ to $+50{ }^{\circ} \mathrm{C}$, with an accuracy of $\pm 0.20 \%$ for water and $-50^{\circ}$ to $0^{\circ}$, with an accuracy of $\pm 0.20 \%$. 


\section{The k-factor}

If the height profile of refractivity is linear, i.e. the refractivity gradient is constant along the ray path; a transformation is possible that allows propagation to be considered as rectilinear. The transformation is to consider a hypothetical earth of effective radius $R_{e}=k a$ as reported by [14].

Thus, the k-factor or the effective earth radius factor is given by [15] as in (5):

$$
\frac{1}{k a}=\frac{1}{a}+\frac{d n}{d h}=\frac{1}{R_{e}}
$$

Where, $\mathrm{k}$ is radius of curvature of the ray path, $d n / d h$ is vertical gradient of refractive index, $R_{e}=$ equivalent earth radius, $a$ is the actual earth radius $(6370 \mathrm{~km})$, and $k$ is the effective earth radius factor ( $\mathrm{k}$-factor). With this geometrical transformation, ray trajectories are linear, irrespective of the elevation [14]. From (5), $k$ can be deduced by:

$$
k=\frac{1}{\left(1+a \frac{d n}{d h}\right)}
$$

Also, on long-term basis, $\mathrm{N}$ varies with height $\mathrm{h}(\mathrm{km})$ as recommended by [9]:

$$
n(h)=1+N_{o} \times 10^{-6} \exp ^{\frac{-h}{h_{o}}}
$$

Where $N_{o}$ is the average value of atmospheric refractivity extrapolated to sea level, $h_{o}$ is the scale height in $(\mathrm{km})$ and $\mathrm{h}$ is the height of the earth's surface above the sea level $(\mathrm{km})$ potential, and from (7) we obtain (8):

$$
\frac{d n}{d h}=-\frac{N_{o}}{h_{o}} \times 10^{-6} \exp \exp \left(\frac{-h}{h_{o}}\right)
$$

\section{E. The Radio Horizon Distance}

The k-factor is useful in the determination of radio horizon distance measured in $(\mathrm{km})$, is the radio ray with the transmitter at certain height and for calculation of the Fresnel zone clearance as given by:

$$
d=\sqrt{2 R_{e} h_{t}}=\sqrt{2 k a h_{t}}
$$

Where $d$ is the distance to the radio horizon, and $h_{t}$, height of the transmitter antenna $(\mathrm{km})$.

\section{DISCUSSION OF RESULTS}

The monthly mean of hourly surface radio refractivity $\left(\mathrm{N}_{\mathrm{s}}\right)$ over Sokoto for the months of January to December (20082010) computed from hourly average values of temperature, pressure and relative humidity were analyzed and presented as depicted in Fig. 1-10.

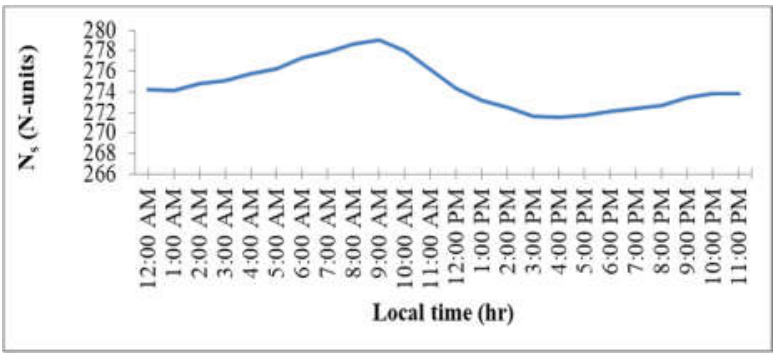

Fig. 1 Monthly mean of hourly surface radio refractivity $\left(\mathrm{N}_{s}\right)$ over Sokoto, January

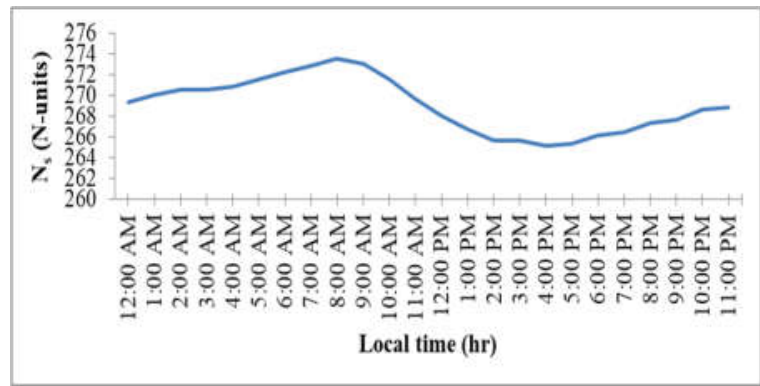

Fig. 2 Monthly mean of hourly surface radio refractivity $\left(\mathrm{N}_{s}\right)$ over Sokoto, February

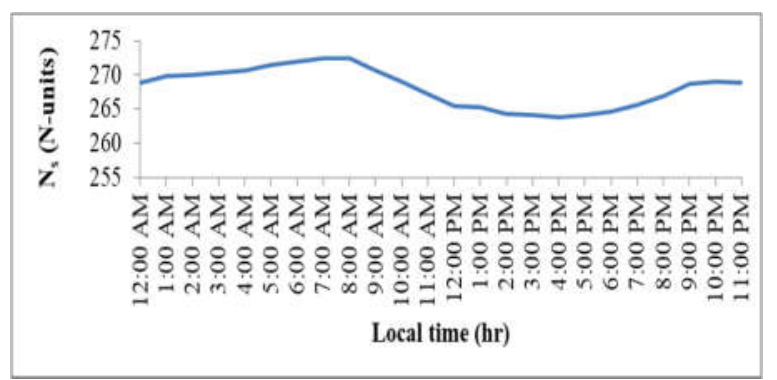

Fig. 3 Monthly mean of hourly surface radio refractivity $\left(\mathrm{N}_{s}\right)$ over Sokoto, March

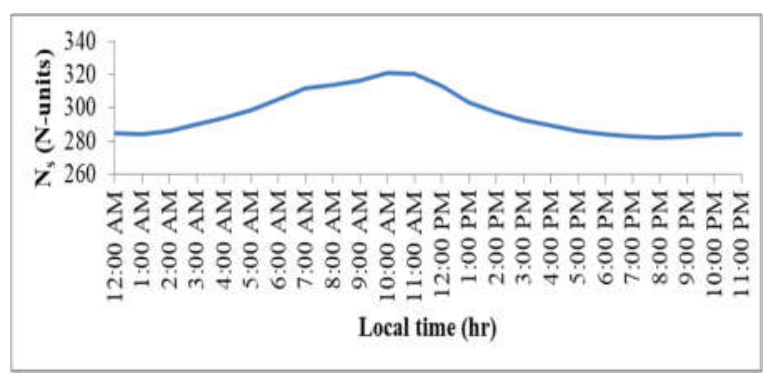

Fig. 4 Monthly mean of hourly surface radio refractivity $\left(\mathrm{N}_{s}\right)$ over Sokoto, April 


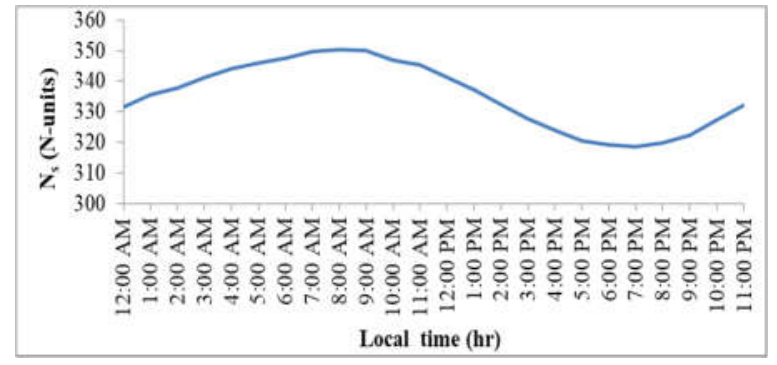

Fig. 5 Monthly mean of hourly surface radio refractivity $\left(\mathrm{N}_{s}\right)$ over Sokoto, May

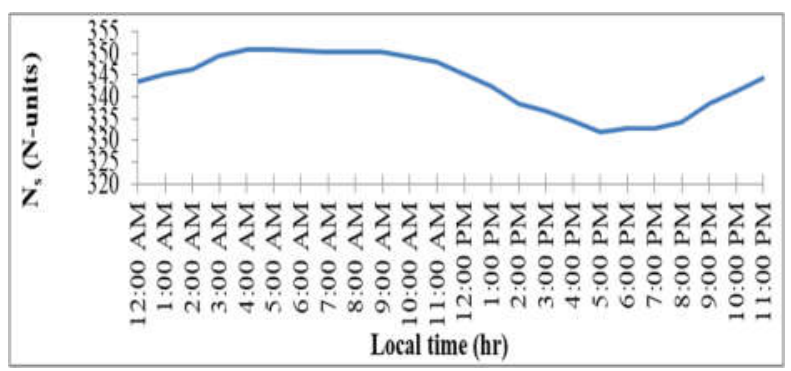

Fig. 6 Monthly mean of hourly surface radio refractivity $\left(\mathrm{N}_{s}\right)$ over Sokoto, June

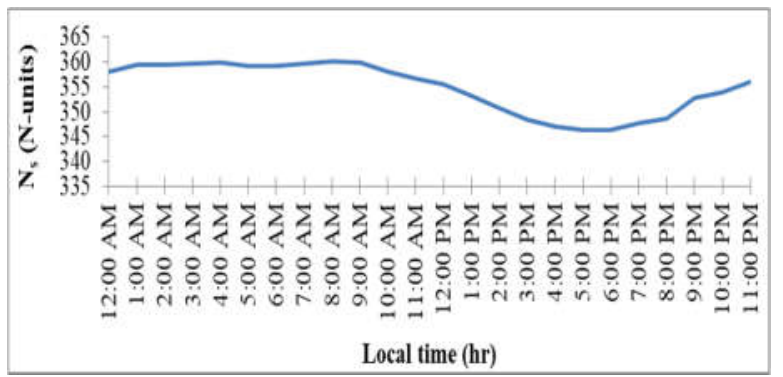

Fig. 7 Monthly mean of hourly surface radio refractivity $\left(\mathrm{N}_{s}\right)$ over Sokoto, July

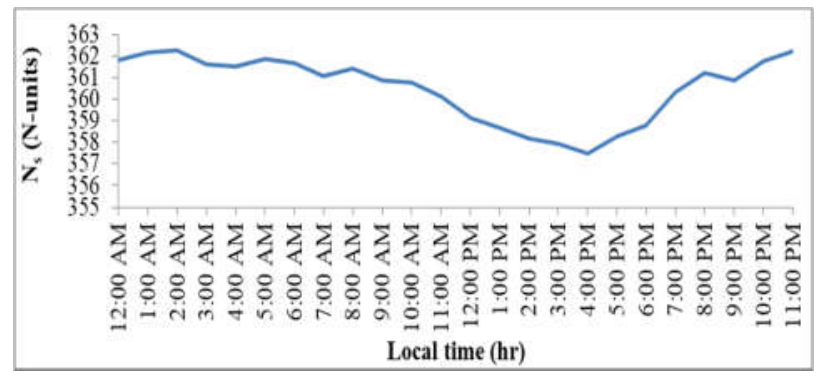

Fig. 8 Monthly mean of hourly surface radio refractivity $\left(\mathrm{N}_{s}\right)$ over Sokoto, August

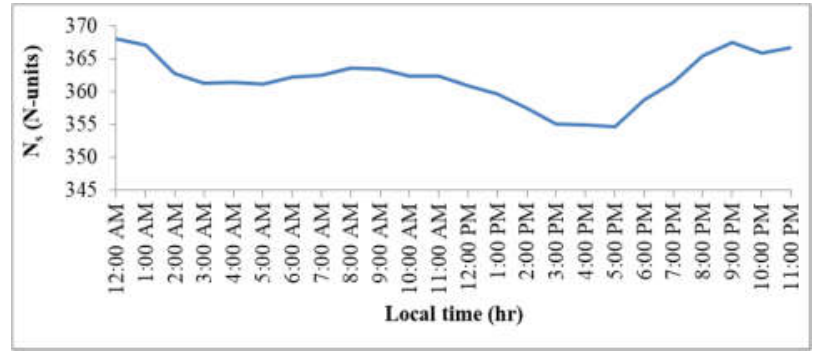

Fig. 9 Monthly mean of hourly surface radio refractivity $\left(\mathrm{N}_{s}\right)$ over Sokoto, September

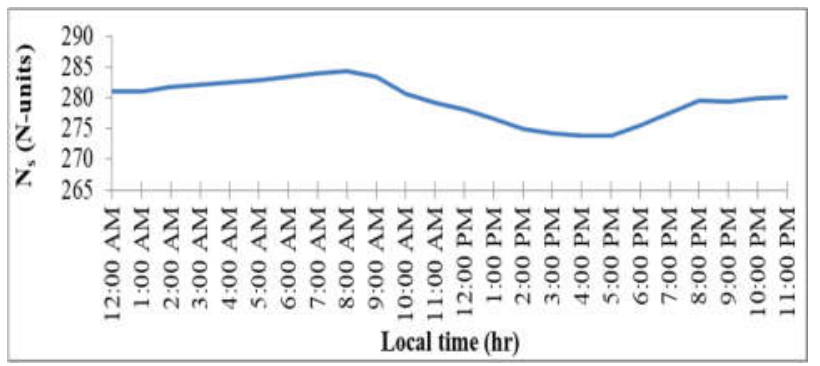

Fig. 10 Monthly mean of hourly surface radio refractivity $\left(\mathrm{N}_{s}\right)$ over Sokoto, December

Figs. 1-10 reveal that monthly mean of hourly surface radio refractivity $\left(\mathrm{N}_{\mathrm{s}}\right)$ over Sokoto display almost similar variability pattern with high values of Ns recorded at night and early morning hours and low values recorded during the afternoon hours of the days. $\mathrm{N}_{s}$ value begins to increase linearly from 12:00 am to a maximum value at 09:00 am and starts to decline to minimum value around 03:00 pm, then begins to increase again from 04:00 pm. There is slight difference of $\mathrm{N}_{\mathrm{s}}$ variability pattern for September (20082010), which could be because the $N_{s}$ is higher in the early morning hours compared to the values recorded at noon, but does not increase linearly until the peak value is attained. Low average $\mathrm{N}_{\mathrm{s}}$ value of about $298 \mathrm{~N}$-units was recorded during afternoon hours and high value of about $309 \mathrm{~N}$-units was recorded during the early morning hours in Sokoto (2008-2010). The low value of $\mathrm{N}_{\mathrm{s}}$ during the afternoon hours could be as a result of high temperature and low humidity, which mixed and made moisture contents low during this period of the day, while the high value of $\mathrm{N}_{s}$ in the early morning hours is due to low temperature and increased humidity with high moisture contents during that period of the day. The results presented are in agreement with [15], who reported a mean surface refractivity of Lapai and Makurdi as 342 and $343 \mathrm{~N}$-units respectively. 


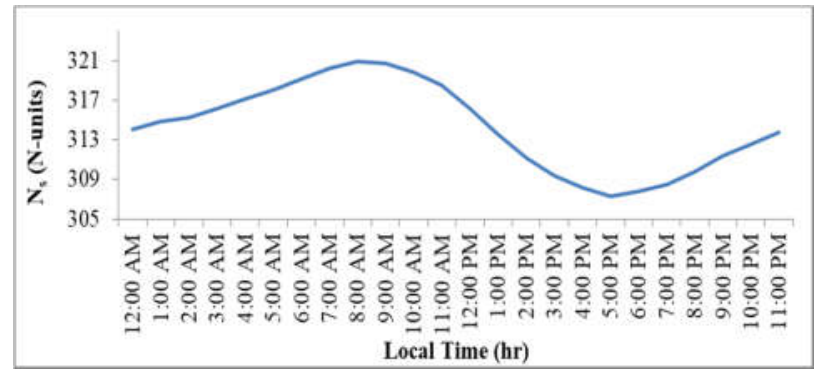

Fig. 11 Monthly mean of hourly surface radio refractivity $\left(\mathrm{N}_{s}\right)$ over Sokoto

The monthly mean hourly surface refractivity over Sokoto (2008-2010) in Fig. 11 shows that surface radio refractivity is high (321 N-units) at 09:00 am in the morning and low (307 N-units) at 05:00 pm in the afternoon. Hourly variation of $14 \mathrm{~N}$-units in surface radio refractivity is recorded between high values in the morning hours and low values at noon. Monthly average surface radio refractivity of $314 \mathrm{~N}$ units is observed in Sokoto (2008-2010). This is also as a result of high temperature and low humidity resulting in low moisture contents during this period of the day, while the high value of $\mathrm{N}_{\mathrm{s}}$ in the early morning hours could be due to low temperature and increased humidity with high moisture contents during that period of the day. This result is in line with [16] and [17], who reported the mean surface $N$ of 342 $\mathrm{N}$-units and refractivity for Lapai, with refractivity gradient of $-46 \mathrm{~N} / \mathrm{km}$.

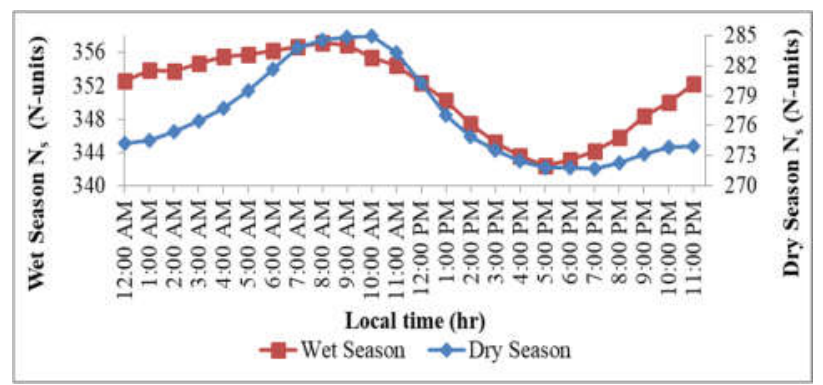

Fig. 12 Dry and wet season mean of hourly surface radio refractivity, Sokoto

Fig. 12 shows the wet and dry season's $\mathrm{N}_{\mathrm{s}}$. The two seasons exhibit similar variability pattern with both seasons recording higher average of $\mathrm{N}_{\mathrm{s}}$ during early morning hours and lower values at afternoon. Dry season average surface radio refractivity varied between $272 \mathrm{~N}$-units and $285 \mathrm{~N}$-units and the wet season recording higher average values of $\mathrm{N}_{\mathrm{s}}$ between $342 \mathrm{~N}$-units and $357 \mathrm{~N}$-units as presented in Fig. 6 . The higher values recorded during the wet season are as result of the Northward movement of the inter-tropical continuity zone (ITCZ), which brings moisture-laden South westerly winds blowing from the Atlantic ocean, while the low values recorded during the dry season are due to the prevalence of dry and dusty North easterly winds blowing from the Sahara Desert. Average seasonal variation of hourly $\mathrm{N}_{\mathrm{s}}$ of $314 \mathrm{~N}$-units is observed in Sokoto (2008-2010). This result is in correspondence with [18], worked on the study of study of surface refractivity over North-Central Nigeria, and reported the mean refractivity over Lapai to be $344 \mathrm{~N}$-units. Further analysis was carried out using surfer 11 on the influence of temperature, pressure, relative humidity and the monthly mean of hourly surface radio refractivity for the month of January 2009 (typical Dry season month) and July 2009 (typical Wet season month) over Sokoto station. From the contour map, it is evident that surface radio refractivity is high during the night and early morning hours, when the temperature is low and decreased rapidly in the afternoon hour and when the temperature is high. Fig. 13-14 are the plots of the results with colour fill of the maps showing the variability of the temperature with the surface radio refractivity over time.

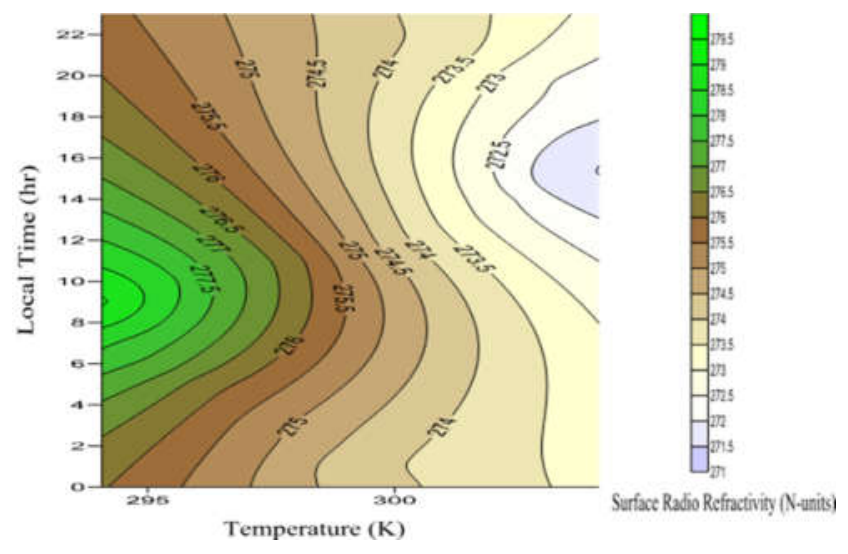

Fig. 13 Monthly mean of hourly temperature and surface radio refractivity for Sokoto, January 2009.

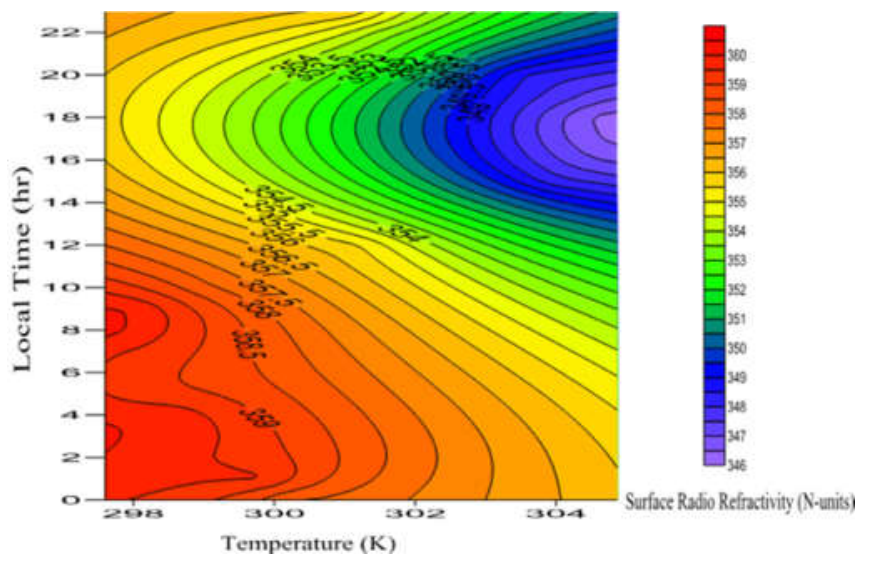

Fig. 14 Monthly mean of hourly temperature and surface radio refractivity for Sokoto, July 2009 
The areas of high surface radio refractivity have tick colour fill as shown by the colour scale, these results are in agreement with [16] and [18].

Surface radio refractivity was constantly high during the night and the early morning hours regardless of the pressure. Surface radio refractivity variation is also relatively dependent on pressure variation, which is the dry term parameter. The colour scale shows the variation of the surface radio refractivity (See Fig. 15-16).

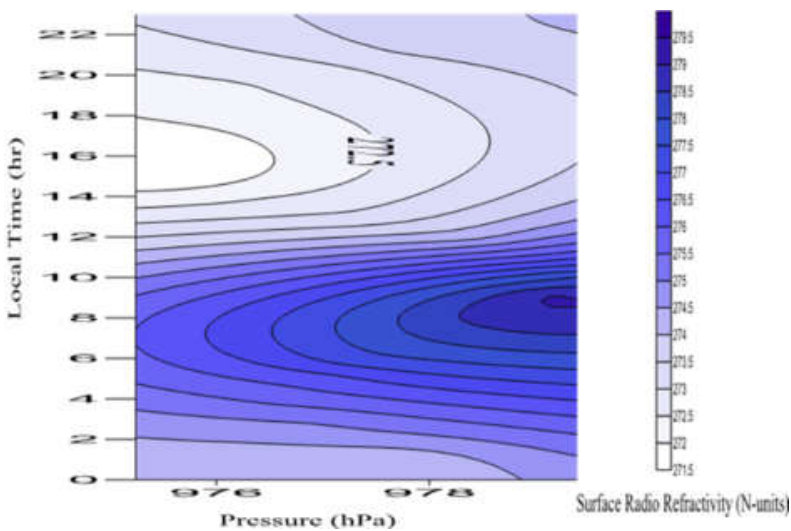

Fig. 15 Monthly mean of hourly pressure and surface radio refractivity for Sokoto, January 2009

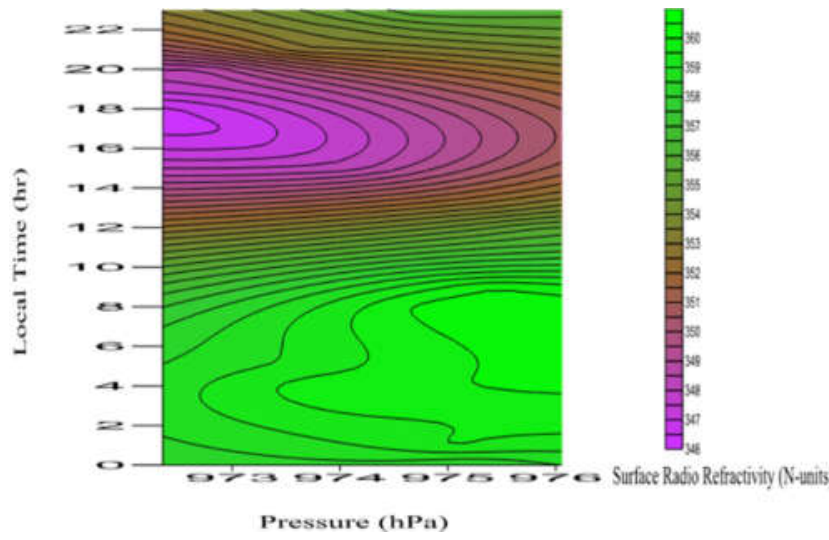

Fig. 16 Monthly mean of hourly pressure and surface radio refractivity for Sokoto, July 2009

Figs. 17-18 show that relative humidity poses major influence on the $\mathrm{N}_{\mathrm{s}}$. Thus, $\mathrm{N}_{\mathrm{s}}$ were high during the night hour and in the early morning hour, when the relative humidity was high and decreased as the relative humidity decreased during the afternoon hours. The high values of $\mathrm{N}_{\mathrm{s}}$ obtained during the night hours and in the early morning hours are attributed to the extensive cloud cover and the saturation of the atmosphere with large amount of moisture content of water vapour, which increased the humidity in the atmosphere during those periods of time.

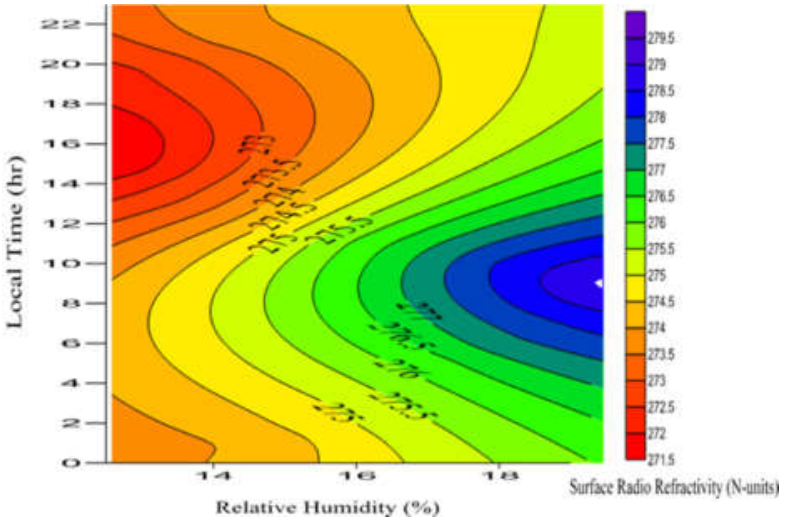

Fig. 17 Monthly mean of hourly relative humidity and surface radio refractivity for Sokoto, January 2009

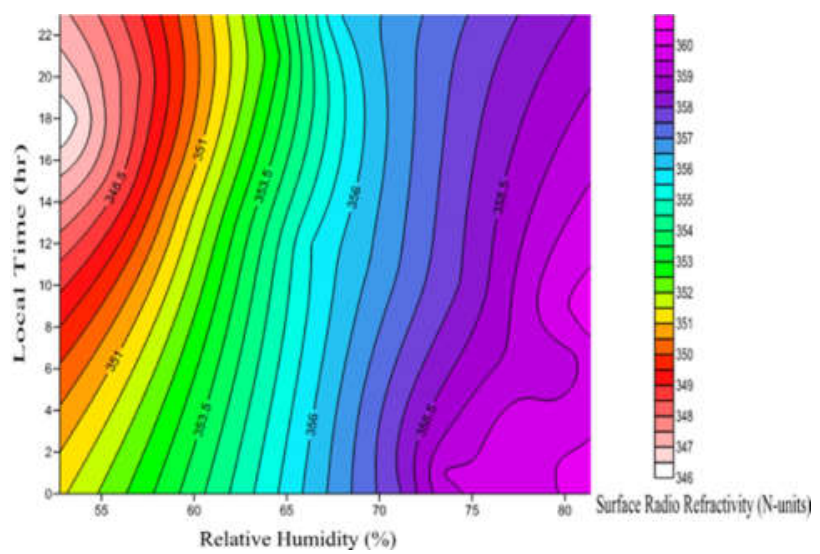

Fig. 18 Monthly mean of hourly relative humidity and surface radio refractivity for Sokoto, July 2009

Monthly mean of hourly radio horizon variation over Sokoto (2008-2010) was plotted as shown in Fig.19.

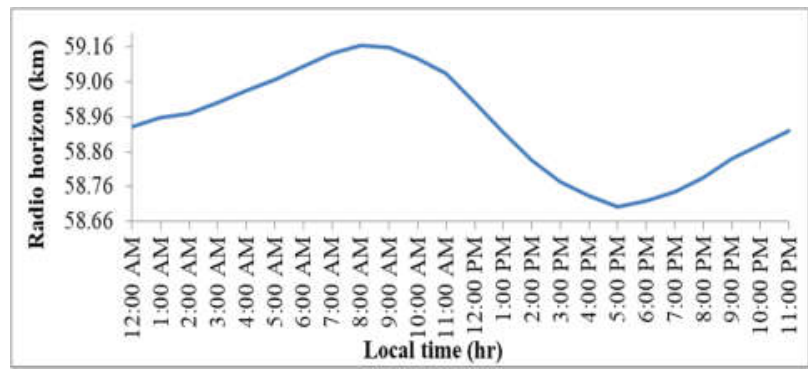

Fig. 19 Monthly mean of hourly radio horizon variability, Sokoto (2008-2010)

From the plot of Figs 19-20, large radio horizon was recorded in the early morning hours with reduced coverage recorded during the afternoon hours of the day. Radio horizon begins to increase linearly from 12:00 am to a maximum coverage at 09:00 am and starts to reduce to minimum coverage around 05:00 pm. Radio horizon begins 
to increase again from 05:00 pm. Average coverage distance of $59.2 \mathrm{~km}$ was recorded in the early morning hours (12:00 am-09:00 am) with minimum coverage distance of $58.7 \mathrm{~km}$ recorded in the afternoon hours $(01: 00 \mathrm{pm}-05: 00 \mathrm{pm})$ at estimated antenna's height of $200 \mathrm{~m}$. Radio horizon variation of about $0.5 \mathrm{~km}$ is observed between morning hours and afternoon hours in Sokoto (2008-2010) The wide radio coverage distance recorded in the early morning hours could be as a result of high surface radio refractivity recorded during that period of the day, and low surface radio refractivity recorded during afternoon hours is responsible for the short radio coverage distance recorded in the afternoon hours. A contour of monthly mean hourly radio horizon variation with surface radio refractivity variation over Sokoto (2008-2010) was also established (Fig. 20).

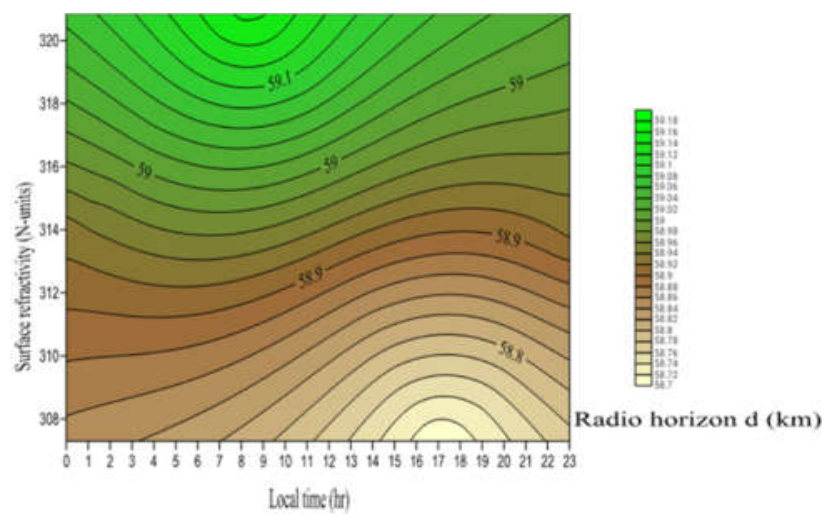

Fig. 20 Monthly mean of hourly radio horizon variation with surface radio refractivity $\left(\mathrm{N}_{s}\right)$, Sokoto (2008-2010)

From the plot, large radio horizon is recorded in the early morning hours, while small coverage recorded during the afternoon hours of the day, the same way with Ns variation. Wide radio coverage distance is recorded when surface radio refractivity is high in the early morning hours and low surface radio refractivity recorded during afternoon hours is responsible for the short radio coverage distance recorded in the afternoon hours as presented by Fig. 20 with the colour scale illustrating the colour variability of the radio horizon. The results reported in this study are in line with works of [15-19]. The authors worked on both Northern and Southern parts of Nigeria.

\section{CONCLUSION}

A monthly mean of hourly $N_{S}$ over Sokoto, Nigeria, has been investigated. The result revealed that surface radio refractivity has diurnal and seasonal tendencies over Sokoto. There is better propagation condition in the morning hours compare to the afternoon hours because radio horizon variation of about $0.5 \mathrm{~km}$ was observed between morning hours and afternoon hours in Sokoto (2008-2010). This has significant implications on radio propagation because the terrestrial relay links at VHF are at higher frequency bands, which is abound in Nigeria may be particularly affected, although this variations are not considered during the design of radio link in Sokoto. Relative humidity and temperature poses major influence on the surface radio refractivity and pressure variation which is the dry term parameter has less influence on the surface radio refractivity. Convincingly, there will be little radio energy loss in the early morning hours than during afternoon hours in Sokoto.

Since atmospheric phenomena are uncontrollable and radio propagation is not fully predictable, radio engineers should make use of the information derived from this research work to give appropriate fade margins in the of design GSM, cellular and other radio communication links in Sokoto for optimal signal reception during various time of the day. The Nigerian Meteorological Agency (NIMET) should provide more weather stations and make local diurnal meteorological data available all over Nigeria, at closer intervals to enable further research to be carried out on diurnal refractivity variations for more reliable results on the prediction of radio propagation conditions in Nigeria.

\section{References}

[1] B. Adeyemi, B, and I. Emmanuel, "Monitoring Tropospheric Radio Refractivity over Nigeria using CM - SAF Data Derived from NOAA-15, 16 and 18 satellites". Ind. J. of Radio and Space Phys., vol. 40, pp. 301-310. 2011.

[2] O. N Okoro, and G. A. Agbo, "The Effect Of Variation of Meteorological Parameters on The Tropospheric Radio Refractivity for Minna". Glob. J. of Sci. Frontier Res., Phys. and Space Sci., vol. 12. 2012.

[3] B. C. Isikwue, Y. A, Kwen, and T. M, Chamegh, "Variations in the Tropospheric Surface Refractivity over Makurdi, Nigeria". Res. J.l of Earth and Planetary Sci., vol. 3, no.2, pp. 50-59. 2013.

[4] T. A, Adediji, and M. O. Ajewole, "Vertical Profile of Radio Refractivity in Akure South-West, Nigeria", Prog. in Electro. Res. C, vol. 4, pp. 157168. 2008.

[5] A. S. Adogoke, and M. A. Onasanya, "Effects of Propagation Delay on Signal Transmission Pacific". J. of Sci. and Tech., vol. 9, no. 1, pp. 13-19. 2008.

[6] B. G. Ayantunji, P. N. Okeke, and J. O. Urama, "Diurnal and Seasonal variations of surface refractivity over Nigeria", Prog. in electromagnetic Research B, vol. 30, pp. 201 - 222. 2011.

[7] O. E. Ekpe, G. A. Agbo, B. G. Ayantunji, N, Yusuf, and A. C. Onugwu, "Variation of Tropospheric Surface Refractivity at Nsukka In South-Eastern Nigeria”. Nig. J. of Space Res., vol. 5, no. 7, pp. 4248. 2009.

[8] R. L. Freeman. "Radio System Design for Telecommunications", 3rd Edition, New York, Wiley-Interscience, John Wiley and Sons, INC, pp. 880. 2007. 
[9] International Telecommunication Union-Radio communication Sector, The radio refractive index: its formula and refractivity data, Rec.ITU-R P.45310. 2012.

[10] J. T. Priestley, and R. J. Hill, "Measuring highfrequency refractivity index in the surface layer". J. of Atm. and Oceanic Tech., vol. 2, no. 2, pp. 233-251. 1985.

[11] S. E. Falodun, and M. O. Ajewole, "Radio Refractivity index in the Lowest 100-m Layer of the Troposphere in Akure, South-Western Nigeria". J. of Atm. and Solar-Terres. Phys., vol. 68, no. 2, pp. 236243. 2006

[12] S. S. Wyer, "A Treatise on producer-gas and gasproducer": The Engineering and Mining Journal, Meeting of the American Institute of Mining, Metallurgical and Petroleum Engineers, London, Retrieved from http://catalog.hathitrust.org/Record/100399220. 1906

[13] International Telecommunications Union-Radio communication Sector. The radio refractive index: its formula and refractivity data, Rec.ITU-R P.453-8. 2001.

[14] International Telecommunication Union-Radio communication Sector. Effects of tropospheric refraction on radio wave propagation, Rec. ITU-R P.834-6. 2007.

[15] Oyedum, O. D., Adediji, A. T., Moses, A. S., and Eiche, J. O. "Spatial Variability of $V H F$ / UHF Electric Field Strength in Niger State, Nigeria". Nigerian Journal of Pure and Applied Physics, Vol. 5, 97-103. 2009.

[16] O. D. Oyedum, B. L. Muhammad, S. A. Abdullahi, B. Ndanusa, and D. Z. Mohammad, "Study of Surface Refractivity Over Lapai and Makurdi (North-Central) Nigeria", Lapai J. of Appl. and Nat. Sci., (LAJANS ), vol. 1, no. 1, pp. 180-195. 2016.

[17] B. L. Muhammad, O. D. Oyedum. B. Ndanusa, A. Y. Jibrin, M. I. Kimpa, and S. A. Abdullahi, "The Study of Diurnal and Seasonal Refractivity Variations and its Influence on VHF/UHF Signal Field Strength Profile Lapai, Nigeria", Nig. J. of Phys., (NJP), vol. 29, no. 1, pp. 1-10. July, 2020.

[18] B. L., Muhammad, "Study of Surface Refractivity over North-Central Nigeria". M. Tech, Physics Dept., Fed. Univ. of Tech. Minna, Nig. St., 2015.

[19] M. B. Ladan, O. D. Oyedum, Y. A Jibrin, B. Ndanusa, I. K. Mohammed, Z. D. Mohammed, A. S Abdullahi, S. Umar and F. Cummings, "Study Of Seasonal Surface Refractivity Over North-Central Nigeria" PHYSICSAccess, ISSN Online: 2756-3898, ISSN Print:2714-500X, 2021. https://doi.org/10.47514/phyaccess.2020.1.2.002 